1

\title{
Multiple-inlet Building Integrated Photovoltaic/Thermal system modelling under varying wind and temperature conditions
}

\begin{abstract}
Air-based, open-loop Building Integrated Photovoltaic/Thermal (BIPV/T) systems are an efficient means for generating electricity and useful heat from incident solar energy. However, due to the low heat exchange efficiency of air, overheating issues may occur that can reduce the electrical production of the system, as well as its durability. With the introduction of multiple intakes of air along the PV string, the goal is to improve the heat extraction from all PV panels, while achieving lower and more uniform PV temperatures.

This study presents the results of a numerical investigation on the comparison of the performance of single and multiple-inlet BIPV/T systems for a possible retrofit or new buildings, with an example of a potential large scale installation on an office building. The comparison was carried out considering a cold winter and a hot summer day, under varying wind conditions, in terms of electrical and thermal performance, and PV temperature distributions. For the modelling of a multiple-inlet BIPV/T system, a flow distribution model was developed utilizing pressure drop and flow correlations, as well as wind tunnel pressure measurements representing the wind effects on the flow distributions, and a modified energy balance model for the multiple-inlet system.
\end{abstract}

It was found that a multiple-inlet BIPV/T system may have up to $1 \%$ higher electrical efficiency corresponding to $7 \%$ additional power to the total output of a $120 \mathrm{~kW}$ system and up to $24 \%$ higher thermal efficiency, while resulting in the lowest and most uniform PV temperatures.

Keywords

Multiple-inlet; BIPV/T; flow modelling; wind effect

Nomenclature

Symbols

A

$A_{\text {b.frame }}$

$\mathrm{A}_{\text {inlet }}$

$\mathrm{c}_{\mathrm{p}}$

$\mathrm{C}_{\mathrm{p}}$

$\mathrm{D}_{\mathrm{h}}$

f

$\mathrm{h}_{\mathrm{c} 1}$

$\mathrm{h}_{\mathrm{c} 2}$

$\mathrm{h}_{\mathrm{o}}$

$\mathrm{h}_{\mathrm{rad}}$

$\mathrm{h}_{\text {wind }}$

K

$\mathrm{K}_{\mathrm{b} \text {.frame }}$

$\mathrm{K}_{\text {inlet }}$

$\mathrm{L}$

$\mathrm{M}$

$\mathrm{Nu}$
Orifice area $\left(\mathrm{m}^{2}\right)$

Back frame opening area $\left(\mathrm{m}^{2}\right)$

Inlet area $\left(\mathrm{m}^{2}\right)$

Specific heat of air $\left(\mathrm{J} / \mathrm{kg} .{ }^{\circ} \mathrm{C}\right)$

Pressure coefficient

Hydraulic diameter (m)

The Darcy friction factor

Convective heat transfer coefficient for the PV layer $\left(\mathrm{W} / \mathrm{m}^{2}{ }^{\circ}{ }^{\circ} \mathrm{C}\right)$

Convective heat transfer coefficient for the insulation layer $\left(\mathrm{W} / \mathrm{m}^{2} .{ }^{\circ} \mathrm{C}\right)$

Exterior film coefficient (combined radiation and convection) $\left(\mathrm{W} / \mathrm{m}^{2}{ }^{\circ}{ }^{\circ} \mathrm{C}\right)$

Radiative heat transfer coefficient $\left(\mathrm{W} / \mathrm{m}^{2}{ }^{\circ} \mathrm{C}\right)$

Wind-induced heat transfer coefficient $\left(\mathrm{W} / \mathrm{m}^{2}{ }^{\circ} \mathrm{C}\right)$

Local loss coefficient for flow through an orifice

Local loss coefficient for flow through the back frame opening

Local loss coefficient for flow through an inlet

Characteristic length of the flow $(\mathrm{m})$

Mass flow rate of the air collector $(\mathrm{kg} / \mathrm{h})$

Nusselt number 
Pressure $(\mathrm{Pa})$

Wind induced external static pressure $(\mathrm{Pa})$

Volumetric flow rate $\left(\mathrm{m}^{3} / \mathrm{s}\right)$

Air channel volumetric flow $\left(\mathrm{m}^{3} / \mathrm{s}\right)$

Inlet volumetric flow $\left(\mathrm{m}^{3} / \mathrm{s}\right)$

$\mathrm{n}$-th channel volumetric flow $\left(\mathrm{m}^{3} / \mathrm{s}\right)$

Flow through the i-th opening $\left(\mathrm{m}^{3} / \mathrm{s}\right)$

Total flow of the air collector $\left(\mathrm{m}^{3} / \mathrm{s}\right)$

Heat transferred to the air stream $(\mathrm{J})$

Flow resistance $\left(\mathrm{kg} /\left(\mathrm{m}^{4} . \mathrm{s}\right)\right)$

Channel flow resistance $\left(\mathrm{kg} /\left(\mathrm{m}^{4} . \mathrm{s}\right)\right)$

Inlet flow resistance $\left(\mathrm{kg} /\left(\mathrm{m}^{4} . \mathrm{s}\right)\right)$

Reynolds number

Radiation absorbed by the PV layer (W)

Ambient air temperature $\left({ }^{\circ} \mathrm{C}\right)$

Entrance air temperature $\left({ }^{\circ} \mathrm{C}\right)$

Temperature of the insulation on the back wall of the BIPV/T $\left({ }^{\circ} \mathrm{C}\right)$

Temperature of air inside the BIPV/T air channel $\left({ }^{\circ} \mathrm{C}\right)$

n-th channel air temperature $\left({ }^{\circ} \mathrm{C}\right)$

External temperature $\left({ }^{\circ} \mathrm{C}\right)$

Temperature of the PV module $\left({ }^{\circ} \mathrm{C}\right)$

Temperature of the adjacent room to the BIPV/T $\left({ }^{\circ} \mathrm{C}\right)$

Insulation layer conductance $\left(\mathrm{W} / \mathrm{m}^{2}{ }^{\circ} \mathrm{C}\right)$

Wind velocity at the height of measurements $(\mathrm{m} / \mathrm{s})$

Pressure drop (Pa)

Pressure drop within i-th channel

Pressure drop across the i-th inlet

Air density $\left(\mathrm{kg} / \mathrm{m}^{3}\right)$

\author{
Building Integrated Photovoltaic/Thermal \\ Coefficient of Performance for heat pump \\ Photovoltaic \\ Unglazed Transpired Collector
}

\section{Introduction}

Solar technologies integrated with the building envelope can be efficiently used for electricity generation and ventilation air preheating, while replacing common building materials, thus increasing the cost effectiveness of the installation (Athienitis et al, 2010). In a BIPV/T system, photovoltaic panels $(\mathrm{PV})$ form the external layer of the building envelope (replacing shingles, rain-screen cladding, etc.) and a channel is formed between the PV layer and the internal skin of the building. In that channel a fluid medium may circulate in an open (only for air) or closedloop configuration (normally water), extracting excess heat from the PV panels via convection, while part of this heat can be recovered and used through various means. Apart from the potential thermal gains, heat extraction from the PV layer results in electrical production enhancement, since, according to Florschuetz (1979), the electrical efficiency of the PV module is a function of its temperature. Thus, low operating PV temperatures can be beneficial for the performance of the systems, especially in large installations. 

heat capacity and density of water. These systems are more suitable for climates with high levels of solar irradiation and ambient temperature. In a review of the state of the art PV/T technology, Chow (2010) referred to experimental and outdoors studies, which showed that water-based $\mathrm{PV} / \mathrm{T}$ systems may have a thermal performance equivalent to a conventional solar thermal collector, with the added electricity production. However, due to their weight, cost and required ducting for the liquid coolant, water-based systems are mainly limited to roof applications. Airbased systems, on the other hand, are more practical for large roof and façade applications in a cold climate since they pose no leakage issues through ducts and joints, there is no need for the addition of anti-freezing additives, they are lighter, easier to install and maintain, while being far less complicated (Bambara et al, 2012; Tyagi et al, 2012).

Heat transfer enhancement techniques for air-based systems have been the subject of several studies. Hegazy (1999) studied variations of glazed and double pass PV/T collectors, with the PV layer set behind a glazing to reduce wind induced heat losses, increasing the thermal efficiency of the system, but also resulting in higher PV temperatures and reduced electrical production. By increasing the air mass flow rate, the PV temperature dropped, at the cost of increased fan consumption. Tonui and Tripanagnostopoulos (2006) investigated additionally the use of fins and a thin metal plate within the air channel. Both techniques improved the performance of the system, the fin system being superior. The incorporation of a solar air heater in series with an airbased BIPV/T system as a means to enhance the thermal output of the system and the outlet air temperature, has also been investigated (Yang and Athienitis, 2014).

The above methods achieved higher thermal efficiencies of the studied systems, but also produced higher PV temperatures. The employment of a continuous air channel causes a vertical temperature stratification of the PV layer. The non-uniform PV temperatures may affect the electrical production, depending on the PV array's connection configuration. For example, if the PV modules of the string are connected in series in the vertical sense, then the PV strings performance will be determined by the performance of the hottest panel. If the PV modules are connected in series horizontally and therefore have similar temperature, then the PV array will consist of strings that perform differently and, naturally, not optimally.

\subsection{Multiple-inlet BIPV/T}

A potential method that could counter the effect of temperature stratification and yield lower PV temperatures employs more than one opening on the PV system along the flow path of the air channel (Figure 1).

Separate channels are created, one for each PV module, which are interconnected, forming a multiple-inlet system. This system aims to enhance heat extraction from each of the PV modules, by regulation of the flow, as well as the boundary temperature of air entering each channel, which is a mixture of air from the previous channel and outside air at ambient temperature. This concept evolved from the hybrid UTC-PV/T system designed by Athienitis et al (2010), consisting of a layer of UTC bearing custom made PV modules fixed with supports, covering $70 \%$ of the total UTC area. The concept of that system was that the solar collector could also produce electrical energy, increasing its cost-effectiveness, especially in the summer months, when space heating is not needed (except for domestic water heating use). While the overall thermal performance of the hybrid system was lower than that of a UTC, its overall efficiency was found to be $7-17 \%$ higher, based on a coefficient of performance (COP) of a heat pump to 
convert electricity into equivalent heat, assumed to be equal to four (Athienitis et al, 2010; Bambara et al, 2012). The system was modelled assuming uniform suction from the UTC perforations, according to Kutscher (1994), considering the mass flow entering the exposed UTC area and the PV covered area for the energy balance.

Yang and Athienitis (2014) investigated experimentally a two-inlet BIPV/T variation of a singleinlet prototype, previously studied by Candanedo et al (2010). Yang developed Nusselt correlations for the laminar and the turbulent region of the PV and the insulation layer of the collector, which were used to model the improved design with two inlets, intended for inclined roof applications. The thermal performance of the system was further enhanced with the addition of a vertical glazed solar collector. It was found that the thermal efficiency of the two-inlet system was $5 \%$ higher than that of the single-inlet prototype. Furthermore, there was a $1.5^{\circ} \mathrm{C}$ decrease in the peak PV temperature, as well as a marginal increase in the electrical efficiency of the system. It was expected that for larger roof installations of 5-6 $\mathrm{m}$ the temperature decrease would be from $5-10^{\circ} \mathrm{C}$, depending on the flow rate and the wind conditions.

Mizraei et al (2014) investigated experimentally the role of cavity flow on the performance of $\mathrm{BIPV} / \mathrm{T}$ placed on inclined roofs. The experimental configurations included a flat and a stepped arrangement, which was essentially a multiple-inlet formation. The cavity was naturally ventilated and no mechanical air collector potential was investigated; however, it was found that the PV temperatures were significantly lower for the stepped configuration cases, as opposed to the flat roof.

All aforementioned studies assumed uniform air intake from all system openings (Athienitis et al, 2010; Yang and Athienitis, 2014), while neglecting the wind effects on the flow distributions of the system (Dymond and Kutscher, 1997). However, the flow distributions of such a system, depending on the system's geometric features and wind conditions, may be far from uniform. It is therefore important to model these flows, since they define the systems performance, in terms of internal convection. The present study focuses on the development of a multiple-inlet BIPV/T model, which addresses both the inlet flow distributions and the energy performance of the system. The potential performance of a multiple-inlet system, based on a large installation case study, is investigated with the aim to improve the PV temperatures, as well as the electrical and thermal gains, as opposed to a typical single inlet system.

\section{Multiple-inlet BIPV/T modelling}

The modelling of a multiple-inlet system consists of two parts: the flow modelling and the energy balance. Multiple-inlet systems have by definition different flow conditions in every separate channel. These flow conditions are based on the inlet flows and affect the flow rate of each channel and the boundary temperature of air entering each channel, both of which affect, in turn, the internal convection. The amount of air entering each opening of a multiple-inlet system depends on the geometry of the opening and of the flow channel, the total mass flow of the air collector and the effect of wind.

Both flow and energy modelling are based on finite control volume techniques, every PV module and its corresponding cavity/channel forming a control volume.

\subsection{Flow modelling}


The inlet and the channel flows of a multiple-inlet BIPV/T system form a complex flow network with interconnected flow paths. A useful representation of flow networks, especially when dealing with complex flows, is the electrical network analogy (Aynsley, 1997).

There are several methods for solving complex nonlinear flow networks the branches of which form closed loops, such as the Hardy Cross method, which calculate the flow through an infinite number of loops and nodes making use of the first two laws of Kirchoff for mass and potential conservation.

Such methods have been used for the modelling of trickle ventilators (Karava et al, 2003), wind driven flows and pressure distributions in buildings, and compartmentalized double screen facades (Lou et al, 2012; Aynsley, 1997). Dymond and Kutscher (1997) used pipe network methods for the calculation of the flow distributions in transpired solar collectors, in an effort to improve the poor flow distribution occurring in large building installations. The absorber was modelled with a three-dimensional set of fictitious pipes and using relations for pressure drop across the plenum, within the air collector, due to buoyancy and due to flow acceleration. A major assumption of the model was that wind effects were considered insignificant given that the pressure difference across the absorber is more than $25 \mathrm{~Pa}$.

This study employs the electrical network analogy for the modelling of the complex flow network that is formed within a multiple-inlet BIPV/T system. A schematic of this general is shown in Figure 2.

The wind effects, represented as equivalent exterior pressure sources, and interior nodes of two consecutive inlets form a closed loop. The main principles upon which the flow modelling is based are mass continuity (1) and conservation of energy (2):

$$
\begin{aligned}
& \sum_{i=1}^{n} Q_{\text {opening }(i)}=Q_{\text {tot }} \\
& \Delta P_{\text {opening }(i)}+\Delta P_{\text {channel }(i)}-\Delta P_{\text {opening }(i+1)}+P_{(i+1)}-P_{(i)}=0
\end{aligned}
$$

Conservation of energy is applied to each of the closed loops formed in the flow network in the form of pressure drop. The sum of pressure drops in a closed loop should be equal to zero, as expressed in equation 2 , where $\Delta \mathrm{P}_{\text {opening(i) }}$ is the pressure drop from flow across the i-th inlet (flow through an orifice) $(\mathrm{Pa}), \Delta \mathrm{P}_{\text {channel(i) }}$ is the frictional pressure drop from flow within the $\mathrm{i}$-th air channel and from flow through the back frame of the PV panels $(\mathrm{Pa})$ and $\mathrm{P}_{(\mathrm{i})}$ is the pressure exterior to the i-th inlet, defined by the local wind effects $(\mathrm{Pa})$.

The general form of the pressure drop-flow correlation for the electrical network representation is:

$$
\Delta P=Q \cdot R
$$

There are two types of pressure drop in a multiple-inlet system: from flow across the inlets and from flow within the air channel. The system's inlets are less than $2 \%$ of the BIPV/T area, therefore, according to Lo et al (2012), pressure driven flow may be assumed, described by the orifice equation (5). The pressure drop from flow within the air channel is a combination of 
frictional losses, described by the Darcy-Weisbach equation (4), as well as pressure drop from flow across the back part of the air channel, due to the sharp entrance of the PV frame, in case of a framed configuration, also described by the orifice equation (5).

$$
\begin{aligned}
& \Delta P=f \cdot \frac{L}{D_{h}} \cdot \frac{\rho \cdot V^{2}}{2} \\
& \Delta P=\frac{1}{2} \cdot K \cdot \rho \cdot Q^{2} / A^{2}
\end{aligned}
$$

For the friction factor $f$, used in the Darcy-Weisbach equation, empirical correlations were used for the modelling process:

- For laminar flow $(\operatorname{Re}<2300)$ :

$$
f=64 / \operatorname{Re}
$$

For the turbulent regime, several empirical relationships have been suggested (Hegazy, 1999 Balocco, 2001; Ghani et al, 2012). This study uses the one proposed by Ghani et al (2012), which also has good agreement of results with equation (5) for the laminar region:

$$
f=(0.79 \cdot \ln (\mathrm{Re})-1.64)^{-2}
$$

The resistances, $R$, are derived from the linearization of equations (4) and (5):

- Inlet Resistance

$$
R_{\text {inlet }}=\left(\frac{K_{\text {inlet }}}{A_{\text {inlet }} 2}\right) \cdot \frac{Q_{\text {inlet }}}{2} \cdot \rho
$$

- Channel resistance

$$
R_{\text {channel }}=\left(\mathrm{f} \cdot \frac{L}{D_{h}}+K_{b . \text { frame }}\right) \cdot \frac{Q_{\text {channel }}}{2 \cdot A_{\text {b.frame }}{ }^{2}} \cdot \rho
$$

The loop energy conservation becomes:

$$
Q_{\text {inlet }(i)} \cdot R_{\text {inlet }(i)}+Q_{\text {channel }(i)} \cdot R_{\text {channel }(i)}-Q_{\text {inlet }(i+1)} \cdot R_{\text {inlet }(i+1)}+P_{(i+1)}-P_{(i)}=0
$$

The mass and energy conservation equations may be rewritten and solved in a matrix form using an iterative scheme. It is assumed that the system employs a variable speed fan which at all times provides a constant air mass outflow through a proportional-integral (PI) control loop. A variable speed fan is always recommended for BIPV/T air systems with a closed loop PI control algorithm to maintain desired flow rate and pressure rise relative to ambient. With highly variable wind conditions, inevitably there will be some fluctuation in the total flow rate, but 

expected to be small (typically less than 10\%) which is acceptable for practical applications.

Clearly, the integration of an outdoor air ventilation system with the HVAC system has several research issues, such as the unsteady flow due to wind effects, which may in turn cause several problems (noise, vibrations). However, these issues are not addressed in the present study, but will be part of a future study focusing on the design and control aspects of such a system.

\subsection{Wind effects}

The local pressure exterior to the inlets of the system is a result of the local wind effects. The wind-induced pressure over the BIPV/T area were implemented in the modelling through wind tunnel testing, for various wind directions, on a scaled model of an existing office building (Figure 3).

The available $80 \mathrm{~m} \times 10 \mathrm{~m}$ retrofit area was assumed to be covered by $2 \mathrm{~m} \times 1 \mathrm{~m}$ framed PV modules, thus forming $40 \mathrm{PV}$ strings of 10 modules each. A $203 \mathrm{~mm}$ x $27.5 \mathrm{~mm}$ Plexiglas façade, equipped with 28 pressure taps, was created to represent the retrofit area (Figure 4).

Wind measurements are difficult to generalize due to the uniqueness of each building features and surroundings. However, a general assessment of pressure distributions over a retrofit area, for various angles of incidence of oncoming wind, may provide input on the expected performance of a multiple-inlet system, as well as design insight concerning the amount and placement of the inlets, based on the prevailing local winds.

The model was tested for an open field exposure, with a flow exponent of $\alpha=0.13$, and for 5 directions of oncoming wind, based on the actual building orientation and the prevailing local wind conditions for Montreal (Fig. 5). The measurement results were input in the flow distribution model as boundary conditions in a similar way as Lo et al (2012). In the aforementioned study, averaged wind-induced pressures were measured in a boundary layer wind tunnel (BLWT) near the openings (windows) of the test model and then used as pressure boundary conditions for CFD analysis of wind-induced cross ventilation. The coupled BLWTCFD results showed good agreement with time-averaged full scale measurements in terms of overall airflow rate from the openings.

Figure 6 demonstrates the pressure coefficient contours, $\mathrm{C}_{\mathrm{P}}$, (the ratio of the static pressure at each point of measurement, over the dynamic pressure of wind), for five angles of oncoming wind over the BIPV/T area, as acquired through the wind tunnel testing:

The first and the second case $\left(0^{\circ}\right.$ and $45^{\circ}$ wind $)$, seem to create the highest pressure coefficient distributions in the vertical sense. For a PV string this would mean highly varying pressure values at each inlet of the system which could lead to outflow at the locations under suction for an improperly designed system.

The directions of $135^{\circ}$ and $180^{\circ}$ created uniform pressure coefficient distributions over the test area and the $90^{\circ}$ wind resulted in vertical regions of approximately the same pressure conditions, which would have small effect on the inlet flow distributions.

\subsubsection{Multiple-inlet BIPV/T energy balance}


The energy balance of a multiple-inlet BIPV/T is modelled using the finite control volume method, with each of the separate channels (and PV modules) of the system comprising a control volume $(\mathrm{CV})$. The main difference from the known BIPV/T energy balance is that, by definition, each CV has a different flow rate (and therefore different Reynolds and Nusselt number) and air temperature boundary conditions, as shown in Figure 7. These parameters were calculated for each channel (or CV) individually, according to the inlet and channel flows as acquired from the flow model, in order to model the multiple-inlet system as accurately as possible, while maintaining a reasonable level of simplicity of the model.

The various cases of flow conditions for the inlets and the channels, as well as the resulting boundary conditions for the air temperature entering each control volume are demonstrated in Figure 8.

For each channel/CV, the subscript " $i$ " denotes the end of the n-th CV closer to the n-th inlet, while the subscript "o", the end closer to the system's outlet.

\subsection{Modelling assumptions}

The secondary loss factors $(\mathrm{K})$ used in the flow distribution model were assumed from the literature (ASHRAE) on duct design. The Nusselt number correlation used in this study were those developed by Yang and Athienitis (2014), who studied a similar system with two inlets and performed a numerical study on a four-inlet system.

The wind effects investigated in this study concerned the effect of wind induced pressure distributions on the inlet flow distributions, not wind induced convection on the exterior of the BIPV/T. An average relationship connecting local wind velocity and external convection was used, similar to the ones developed by Liu \& Harris (2007):

$$
h_{\text {wind }}=6 \cdot V_{l o c}+4
$$

For simplicity, only one wind reference speed is considered and not the actual velocity distributions over the BIPV/T area. This, according to Vasan and Stathopoulos (2014) may lead to overestimation of the heat exchange efficiency and underestimation of the wind-induced losses.

\section{Simulations}

The models developed in part 2 were used for the simulation of the performance of two multipleinlet BIPV/T systems considered for the assumed office building. The PV modules were assumed to have a nominal efficiency of $15 \%$, with an output of $300 \mathrm{~W}$, forming a $120 \mathrm{~kW}$ system.

Two single-inlet systems were also considered as a reference technology. Each type of system had identical openings for the intake of air, but varied by channel gap size $(0.10 \mathrm{~m}$ and $0.15 \mathrm{~m})$ to account for its effect on the flow (Figures 9 and 10). "In summary, the systems considered are the following:

- System I: Single-inlet system, with $0.10 \mathrm{~m}$ channel gap

- System II: Single-inlet system, with $0.15 \mathrm{~m}$ channel gap 
- System IV: Multiple-inlet system, with $0.15 \mathrm{~m}$ channel gap"

Furthermore, two total mass outflows from the air collector were considered, namely $400 \mathrm{~kg} / \mathrm{h}$ and $800 \mathrm{~kg} / \mathrm{h}$ (with maximum channel air velocities of $0.5 \mathrm{~m} / \mathrm{s}$ and $1 \mathrm{~m} / \mathrm{s}$ respectively) to account for the effect of total air flow on the flow distribution and the energy balance of each channel. All systems were based on framed PV modules $2 \mathrm{~m}$ wide and $1 \mathrm{~m}$ long along the flow path of air inside the air channel, thus creating $10 \mathrm{~m}$ long and $2 \mathrm{~m}$ wide PV strings.

The goal of these simulations was to investigate the flow distributions of the multiple-inlet systems in relation to the system's geometry, total flow rate and wind effects, as well as the performance of a multiple-inlet system against a single-inlet, for typical Montreal weather conditions. The systems were compared in terms of electrical and thermal efficiency, as well as PV temperature uniformity, which is a major factor of consideration for the durability of large PV installations.

These porosities of the inlets were calculated heuristically in two steps: first, the required flows in order to have uniform PV temperatures were evaluated through a trial and error procedure using the energy balance model, assuming ambient still air, i.e. no wind conditions, where the highest PV temperatures were expected. Secondly, having acquired the required flows through each inlet, the flow model was used in order to size the inlets accordingly.

The simulations were carried out for a cold winter and a hot summer day. Assuming a sinusoidal form for the ambient temperature with an average value of $-15^{\circ} \mathrm{C}$ and $20^{\circ} \mathrm{C}$ for the cold and the hot day respectively, with a $\pm 5^{\circ} \mathrm{C}$ swing and a peak at $3 \mathrm{pm}$. The solar irradiation was calculated assuming clear days for a surface azimuth of $-58^{\circ}$, according to the actual building orientation. The wind-induced pressures were implemented, as acquired from the wind tunnel testing.

\section{Results and discussion}

\subsection{Flow distributions}

The inlet flows of the two multiple-inlet systems were calculated for $2 \mathrm{~m} / \mathrm{s}$ wind at $45^{\circ}$, and compared to the case of uniform exterior pressure (no wind/ambient still air). In Figure 11, the vertical axis corresponds to the openings 1 through 10 of the system, while the horizontal axis shows the calculated inlet flows, normalized by the total air mass outflow of the air collector. The error bars indicate the variations of the inlet flows for the $40 \mathrm{PV}$ strings of the BIPV/T system from the average flow of the corresponding inlet, due to the pressure distributions induced by the $45^{\circ}$ degree over the BIPV/T area.

\section{Effect of total mass air flow and channel gap size}

Results showed that the ratios of the inlet flows to the total air flow of the air collector remain the same when the latter is changed. For example, if the total flow rate of the air collector is doubled, the flows of each inlet are doubled as well. This was consistent for both gap sizes. Doubling the total flow rate produced decreased wind-driven inlet flow variations.

Reducing the gap size increased the resistance to the flow due to increased friction, as well as reduced flow area resulting in reduced inlet flows for the inlets that are located the farthest from 

resistance reduces the effect of wind on the flow distributions.

\section{Effect of wind velocity and direction.}

As shown in Figure 11, the $2 \mathrm{~m} / \mathrm{s}$ wind at $45^{\circ}$ resulted in the highest variation of the inlet flows from the designed. With increasing wind velocity, these variations became more prominent for all wind directions. However, it was found that for wind velocities higher than $2 \mathrm{~m} / \mathrm{s}$, the PV temperatures for all system types considered dropped drastically and became uniform, due to the dominating wind-driven heat losses. Therefore, the comparison of the systems' performance was carried out for wind velocities up to $2 \mathrm{~m} / \mathrm{s}$.

Tables 2 and 3 summarize the flow distributions of an average PV string for all considered wind directions and for $0 \mathrm{~m} / \mathrm{s}, 1 \mathrm{~m} / \mathrm{s}$ and $2 \mathrm{~m} / \mathrm{s}$ wind velocity. This means that the flow of each inlet is the weighted average of the $40 \mathrm{PV}$ modules comprising a horizontal array. The results showed that the effect of wind for the directions of $90^{\circ}$ and $135^{\circ}$ was minimal for wind velocities up to 2 $\mathrm{m} / \mathrm{s}$.

\subsection{PV temperatures}

The PV temperatures for the $2 \mathrm{~m} / \mathrm{s}$ wind at $45^{\circ}$ were compared to the ones that would occur in the case of $2 \mathrm{~m} / \mathrm{s}$ wind, but with uniform exterior pressure (designed inlet flows).

The vertical axis in Figure 12 indicates the 10 PV modules of the PV string and the horizontal axis the PV temperatures as calculated due to the inlet flow distributions for $2 \mathrm{~m} / \mathrm{s}$ wind approaching at $45^{\circ}$ angle, as well as for the case of uniform exterior pressure. The error bars indicate the variations of the PV temperatures for the $40 \mathrm{PV}$ strings of the BIPV/T system from the average flow of the corresponding inlet, due to the pressure distributions induced by the $45^{\circ}$ degree wind over the BIPV/T area. The plots are for summer conditions, where the highest PV temperatures are expected, for the two channel gap sizes and two total air collector flow rates.

From these results, the following are noted:

- Even the high variations in inlet flows (Figure 11) result in insignificant temperature variations, from the ones that would be expected according to the designed flows $\left( \pm 3^{\circ} \mathrm{C}\right.$ for the system with $0.15 \mathrm{~m}$ channel gap and total mass air flow rate of $200 \mathrm{~kg} / \mathrm{h}$ ).

- The system with $0.10 \mathrm{~m}$ channel gap has smaller temperature variations which correspond to the smaller inlet flow variations.

- The variations are almost eliminated when the total air collection rate is doubled. The 800 $\mathrm{kg} / \mathrm{h}$ air collection rate corresponds to a channel air velocity of approximately $1 \mathrm{~m} / \mathrm{s}$ which is typical for BIPV/T systems.

- The velocity of wind is more crucial than the actual direction on the PV temperatures, concerning the wind effect on the internal convection.

The temperature variations were minimal for the other two wind directions. Higher wind velocities produced higher flow distribution variations. However, with dominating external convection, the PV temperatures for all systems were lower and more uniform. Winter PV temperatures followed a similar pattern but with considerably lower PV temperatures. 
Figure 13 presents a comparison on the uniformity of the modules' temperatures of an average PV string for a $400 \mathrm{~kg} / \mathrm{h}$ total mass flow rate, for summer conditions and three wind velocities and the two channel gap sizes.

Results show the following:

- Increase of the total air mass flow of the air collector results in lower PV temperatures, the differences being more prominent at conditions with no wind. However, with increasing wind velocity, external convection dominates and the differences are lower.

- Increasing wind velocity results in lower PV temperature variations along the same string.

- In all cases, the multiple-inlet systems produce uniform PV temperature distributions, with small temperature differences between panels and with the lowest overall PV temperatures.

- Even at a lower total mass flow rate of the air collector, the multiple-inlet system maintains low and uniform PV temperatures along the PV string.

The PV temperature profiles were similar for the air collection rate of $800 \mathrm{~kg} / \mathrm{h}$, the temperatures being lower.

\subsection{Electrical and thermal efficiency}

Figures 14 and 15 present plots of the electrical and thermal efficiencies of the systems, for the assumed cases of weather conditions. These efficiencies are calculated according to the total electrical and thermal output of the systems and on the total daily solar irradiation incident on the installations.

The above efficiencies are defined as follows:

- Daily electrical efficiency: Total electrical energy produced over the total daily solar irradiation incident on the BIPV/T surface.

- Daily thermal efficiency: The daily thermal energy extracted and transferred to the air flowing inside the air channel over the total daily solar irradiation incident on the BIPV/T surface.

The single inlet systems had the lowest overall performance, both electrically and thermally. Depending on the weather conditions, wind velocity and air collection rate, a multiple-inlet system may have an increase in electrical efficiency of $0.3 \%-1 \%$ and thermal efficiency increase of $14 \%-25 \%$. It should be noted that the fan consumption has not been addressed in this investigation and the net electrical production should be looked into for a more accurate comparison. The differences in the electrical efficiency of the systems are lower for increasing wind velocity and air collection rate, due to the lower PV temperatures. Also, in accordance with previous studies, higher air collection rates yielded higher thermal efficiency.

\section{Conclusion}

This study introduces a methodology for the modelling of multiple-inlet BIPV/T systems which includes a flow distribution model, incorporating wind effects in the form of exterior pressures, 

inlets and the air channels of the system.

The proposed models were applied for the simulation of two multiple-inlet BIPV/T systems considered for a potential retrofit project of an office building. These were compared with two single inlet system for the same environmental conditions. The simulation results showed that the PV temperatures for the multiple-inlet systems were considerably lower (up to $17^{\circ} \mathrm{C}$, for low wind conditions) with small temperature difference between the coolest and the warmest PV panels $\left(3^{\circ} \mathrm{C}\right.$ to $\left.7^{\circ} \mathrm{C}\right)$. The corresponding temperature difference for the single inlet systems was much higher $\left(8^{\circ} \mathrm{C}\right.$ to $\left.26^{\circ} \mathrm{C}\right)$.

An increase of up to $1 \%$ in electrical efficiency was observed for the multiple-inlet system. For a $120 \mathrm{~kW}$ system, this translates in $7 \%$ higher electrical output. Furthermore, there was a $14 \%$ to $25 \%$ increase in the thermal efficiency, in comparison to the single inlet system, depending on the weather conditions.

The effect of wind direction on the flow distributions and as a result to the internal convection part of the energy balance was found to be insignificant for wind velocities up to $2 \mathrm{~m} / \mathrm{s}$, regardless of the wind direction. Higher wind velocities would be expected to cause more considerable differences; however, with external convection dominating, the performance of all systems investigated would be similarly affected, in that the PV temperatures would be low and uniform, while the thermal gains would be minimal.

\section{Acknowledgements}

The authors would like to acknowledge the support of the Natural Sciences and Engineering Research Council of Canada (NSERC) through an NSERC/Hydro Quebec Industrial Chair.

\section{References}

ASHRAE, 2009, -ASHRAE Handbook of Fundamentals, American Society of Heating, Refrigerating and Air-Conditioning Engineers, Atlanta, GA, USA

Athienitis, A.K., Bambara, J., O’Neill, B., Faille, J. (2010). A prototype photovoltaic/thermal system integrated with transpired collector. Solar Energy 85, 139-153

Aynsley, R.M. (1997). A resistance approach to analysis of natural ventilation airflow networks. Journal of Wind Engineering and Industrial Aerodynamics 67\&68, 711-719

Balocco, C. (2001). A simple model to study ventilated facades energy performance. Energy and Buildings 34, 469-475

Bambara, J., Athienitis, A.K., Karava, P. (2012) Performance Evaluation of a BuildingIntegrated Photovoltaic/Thermal System. International High Performance Buildings Conference, 2012, Purdue 

and steady state models for open-loop air based BIPV/T systems, American Society of Heating, Refrigerating and Air-Conditioning Engineers. Transactions 2010, Vol.116, Part 1, 600-612

Chen, Y., Athienitis, A.K., Galal, K. (2010). Modeling, design and thermal performance of a BIPV/T system thermally coupled with a ventilated concrete slab in a low energy solar house: Part 1, BIPV/T system and house energy concept. Solar Energy 84, 1892-1907

Chow, T. (2010). A review on photovoltaic/thermal hybrid solar technology. Applied Energy 87, 365-379

Dymond, C., Kutscher, C. (1997). Development of a flow distribution and design model for transpired solar collectors. Solar Energy 60, 291-300

Florschuetz, L.W. (1979). Extension of the Hottel-Whilier model to the analysis of combined photovoltaic/thermal flat plate collectors. Solar Energy 22, 361-366

Ghani, F., Duke, M., Carson, J.K. (2012). Effect of flow distribution on the photovoltaic performance of a building integrated photovoltaic/thermal (BIPV/T) collector. Solar Energy 86, $1518-1530$

Hegazy, A.A., (1999). Comparative study of the performances of four photovoltaic/thermal solar air collectors. Energy Conversion \& Management 41, 861-881

Karava, P., Stathopoulos, T., Athienitis, A.K. (2003). Investigation of the performance of trickle ventilators. Building and Environment 38, 981-993

Kutscher, C.F. (1994). Heat exchange effectiveness and pressure drop for air flow through perforated plates with and without crosswind. Journal of Heat Transfer 116, 391-399

Lo, L.J., Banks, D., Novoselac, A. (2012). Combined wind tunnel and CFD analysis for indoor airflow prediction of wind-driven cross ventilation. Building and Environment 60, 12-23

Lou, W., Huang, M., Zhang, M., Lin, N. (2012). Experimental and zonal modeling for wind pressures on double-skin facades of a tall building. Energy and Buildings 54, 179-191

Mizraei, P.A., Paterna, E., Carmeliet, J. (2014). Investigation of the role of cavity airflow on the performance of building-integrated photovoltaic panels. Solar Energy 107, 510-522

Tonui, J.K. \& Tripanagnostopoulos, Y. (2006). Air-cooled PV/T solar collectors with low cost performance improvements. Solar Energy 81, 498-511

Tyagi, V., Kaushik, S., Tyagi, S. (2012). Advancement in solar photovoltaic/thermal (PV/T) hybrid collector technology. Renewable and Sustainable Energy Reviews 16, 1383-1398

Vasan, N., Stathopoulos, T. (2014). Experimental study of wind effects on unglazed transpired collectors. Solar Energy 101, 138-149

Yang, R.J. (2014). Overcoming technical barriers and risks in the application of building integrated photovoltaics (BIPV): hardware and software strategies. Automation in Construction $51,92-102$ 
Yang, T., Athienitis, A.K. (2014). A study of design options for a building integrated photovoltaic/thermal (BIPV/T) system with glazed air collector and multiple inlets. Solar Energy $104,82-92$ 

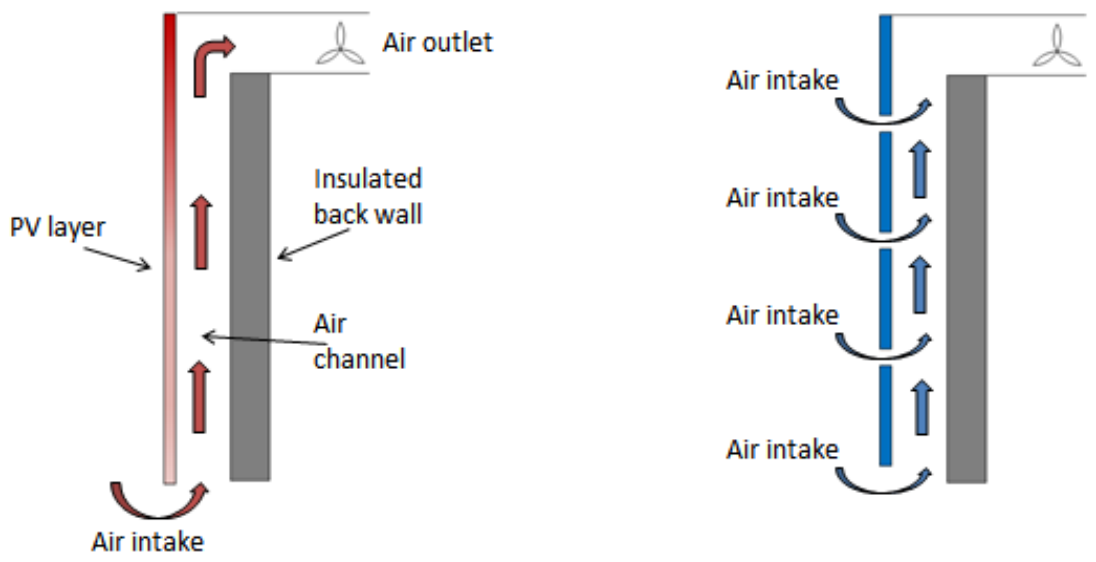

Figure 1: Single and multiple-inlet BIPV/T system.

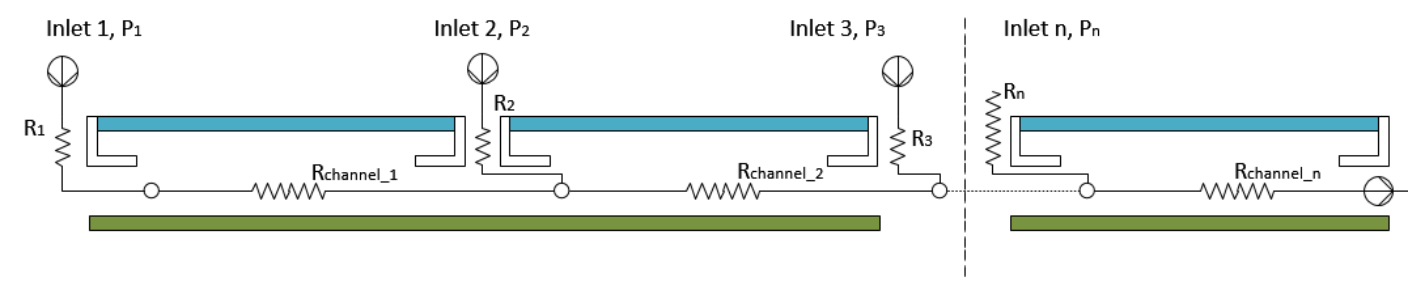

Figure 2: Electrical resistance analogy for flow modelling.

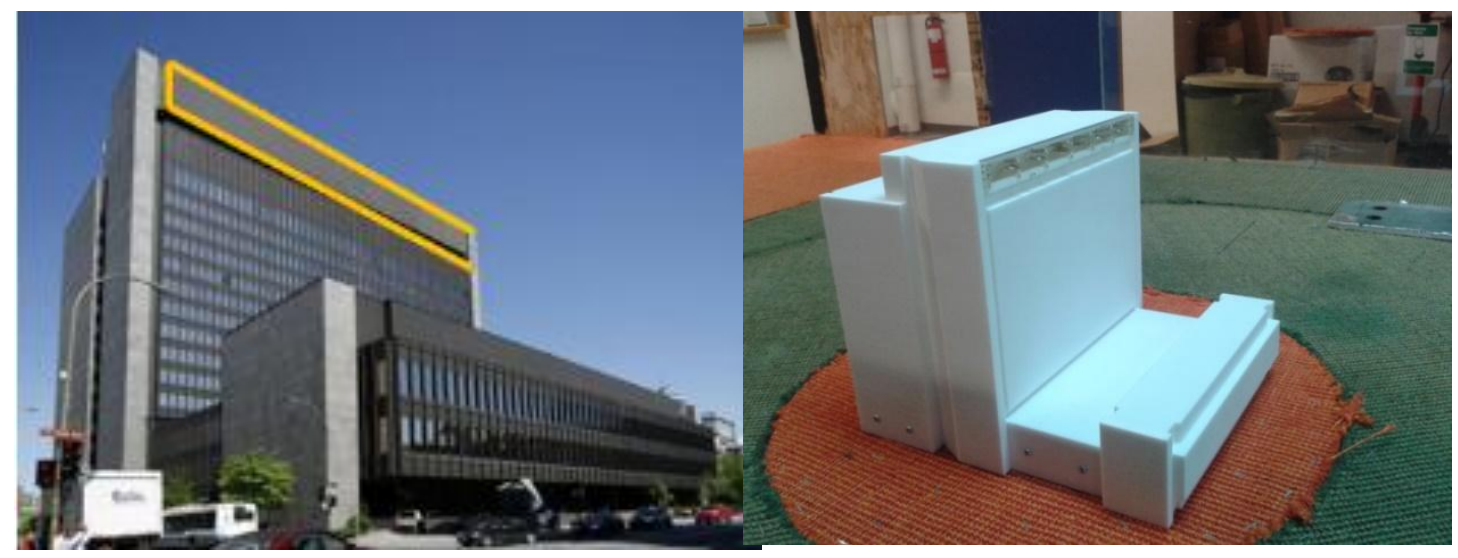

Figure 3: Potential location for BIPV/T retrofit on an office building (highlighted area) and 1:400 scaled model of the building (left).

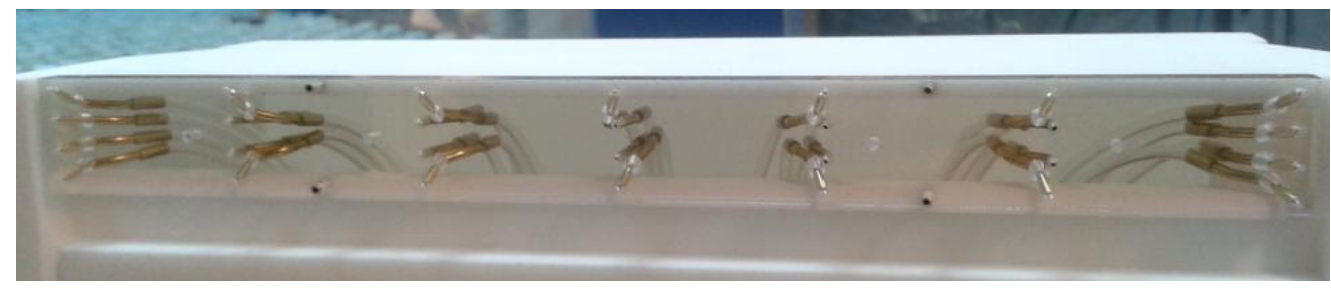

Figure 4: BIPV/T façade for the wind tunnel model, equipped with pressure taps. 

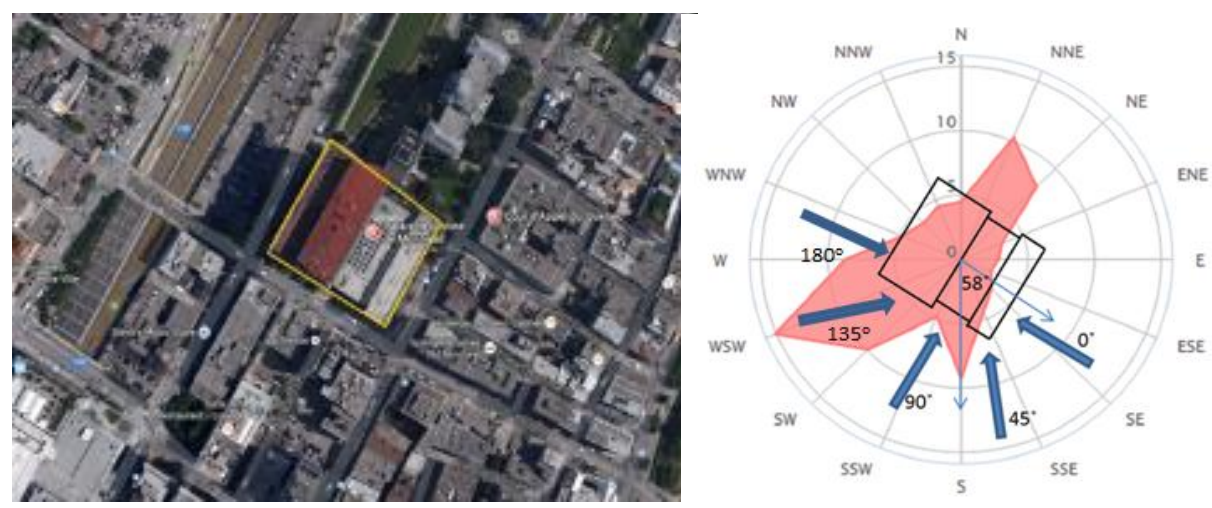

Figure 5: Building orientation, wind rose of Montreal and wind directions tested.

$0^{\circ}$ Wind (perpendicular to the BIPV/T surface)

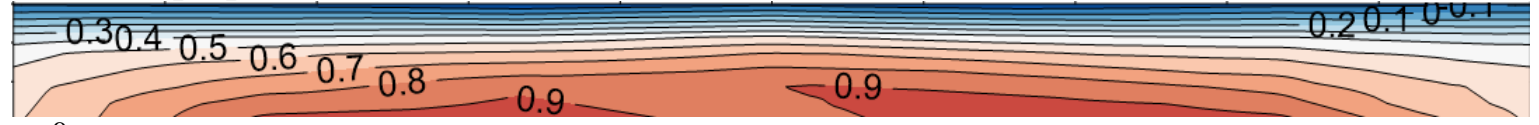

$45^{\circ}$ Wind

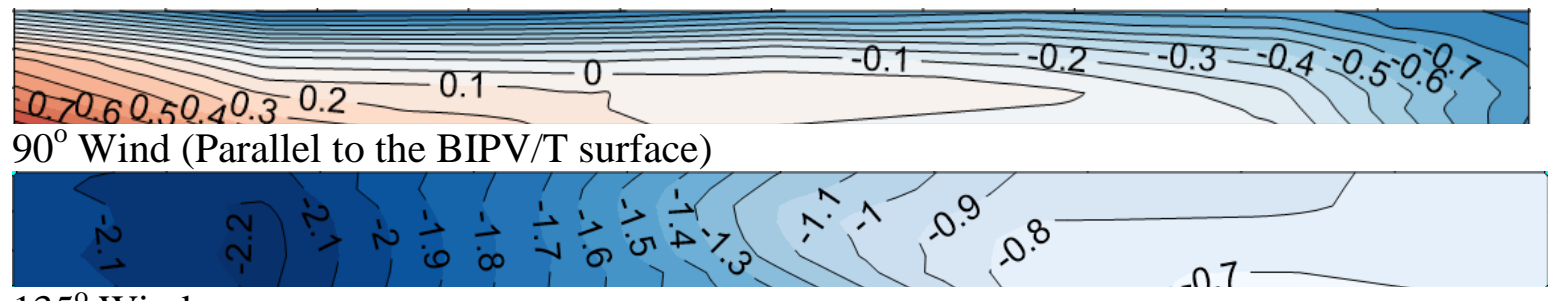

$135^{\circ}$ Wind

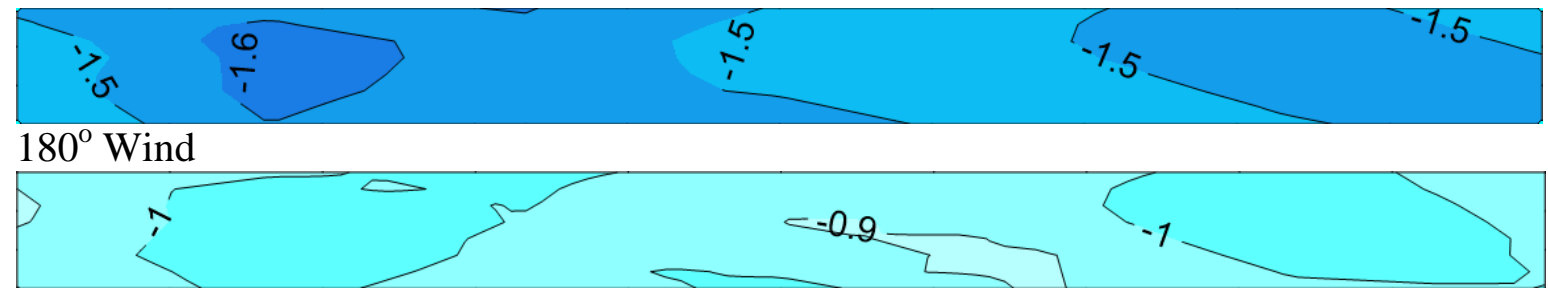

Figure 6: Pressure coefficient distributions on BIPV/T area. From top to bottom: $0^{\circ}, 45^{\circ}, 90^{\circ}, 135^{\circ}$ and $180^{\circ}$ angles of incidence of wind. 


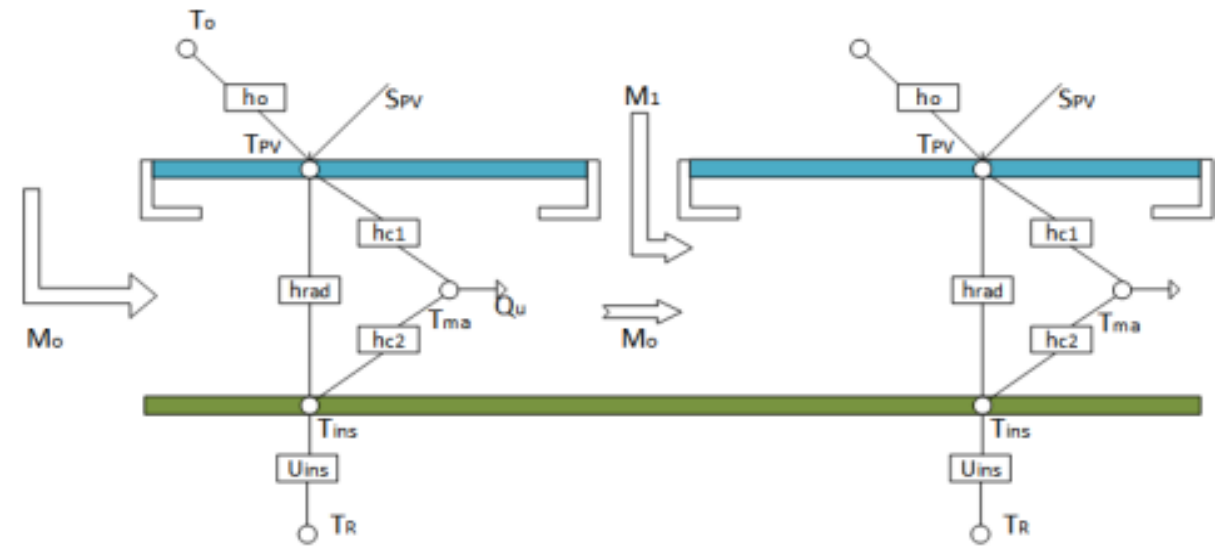

Figure 7: Multiple-inlet BIPV/T energy balance.

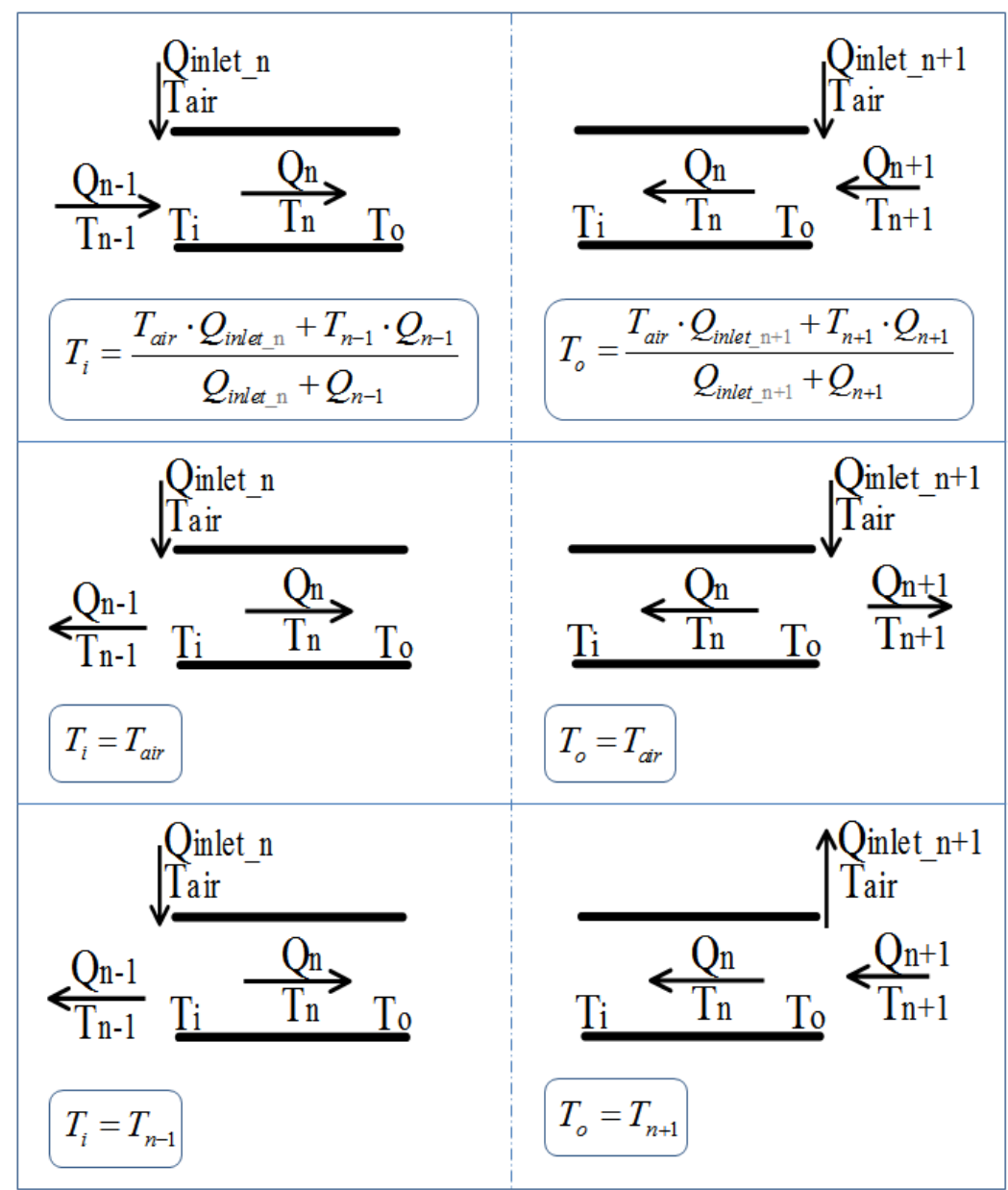

Figure 8: The possible channel flows and channel air temperature inlet boundary conditions. 


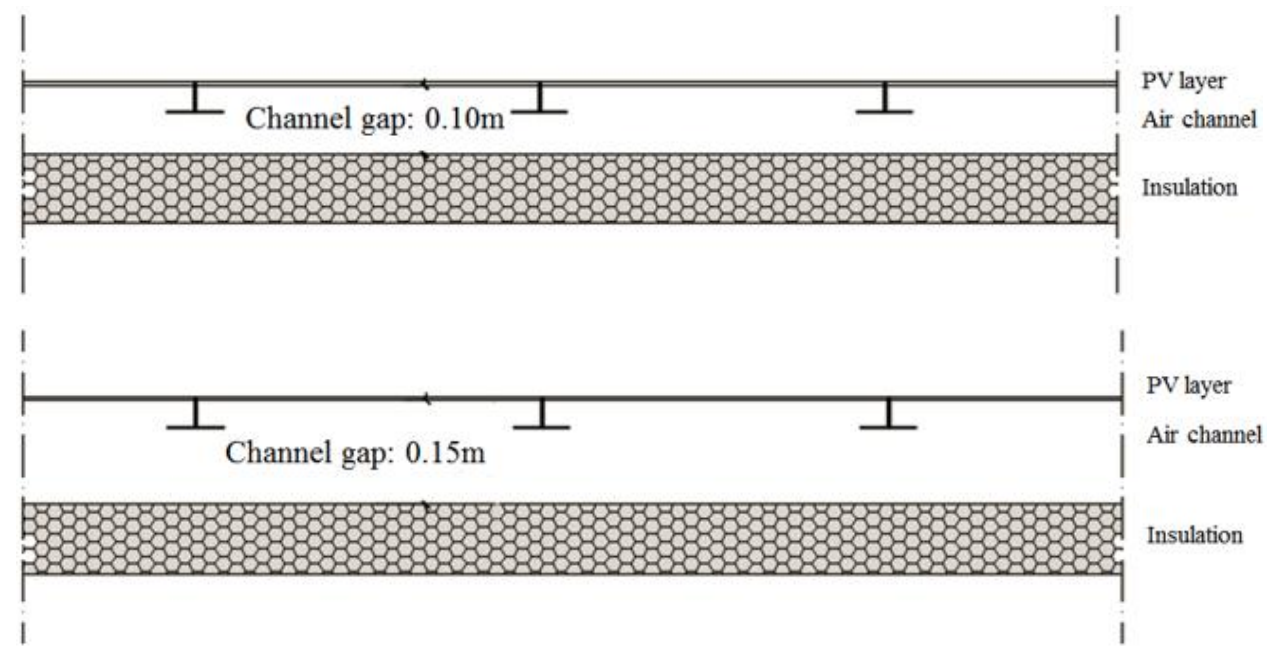

Figure 9: Single inlet systems (Systems I and II with $0.10 \mathrm{~m}$ and $0.15 \mathrm{~m}$ channel gap respectively).

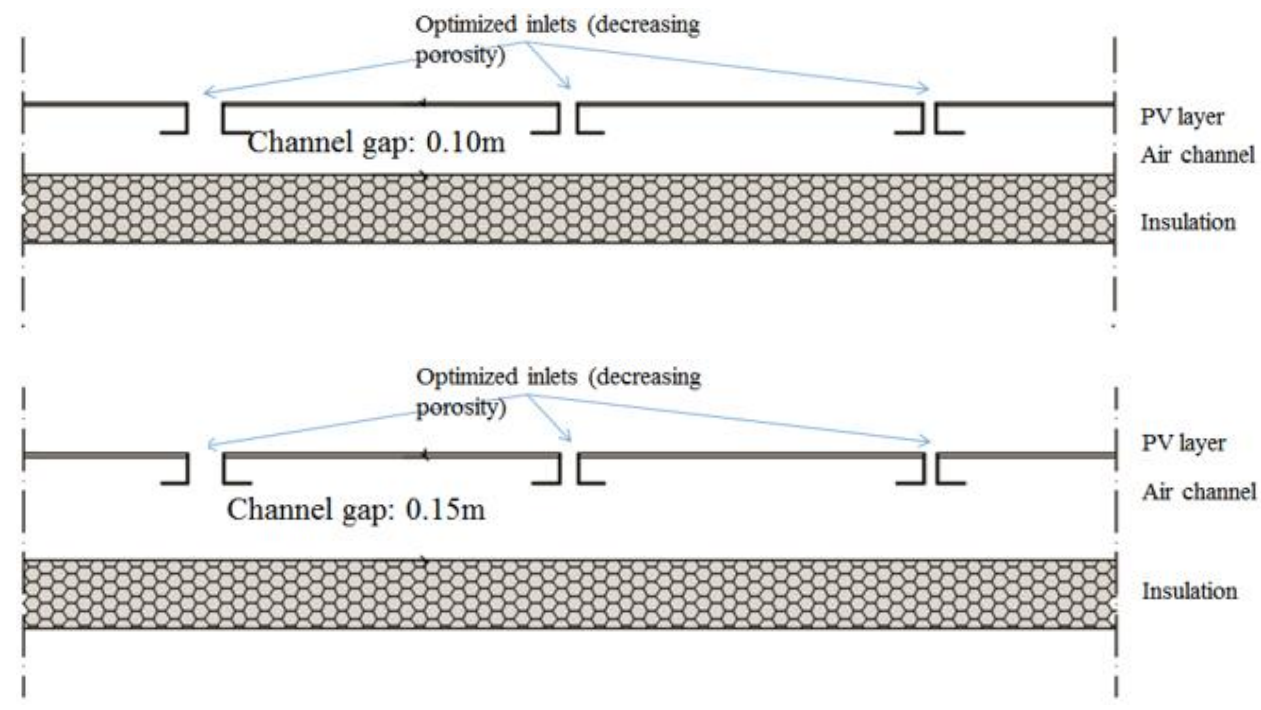

Figure 10: Multiple-inlet systems (Systems III and IV with $0.10 \mathrm{~m}$ and $0.15 \mathrm{~m}$ channel gap respectively). 


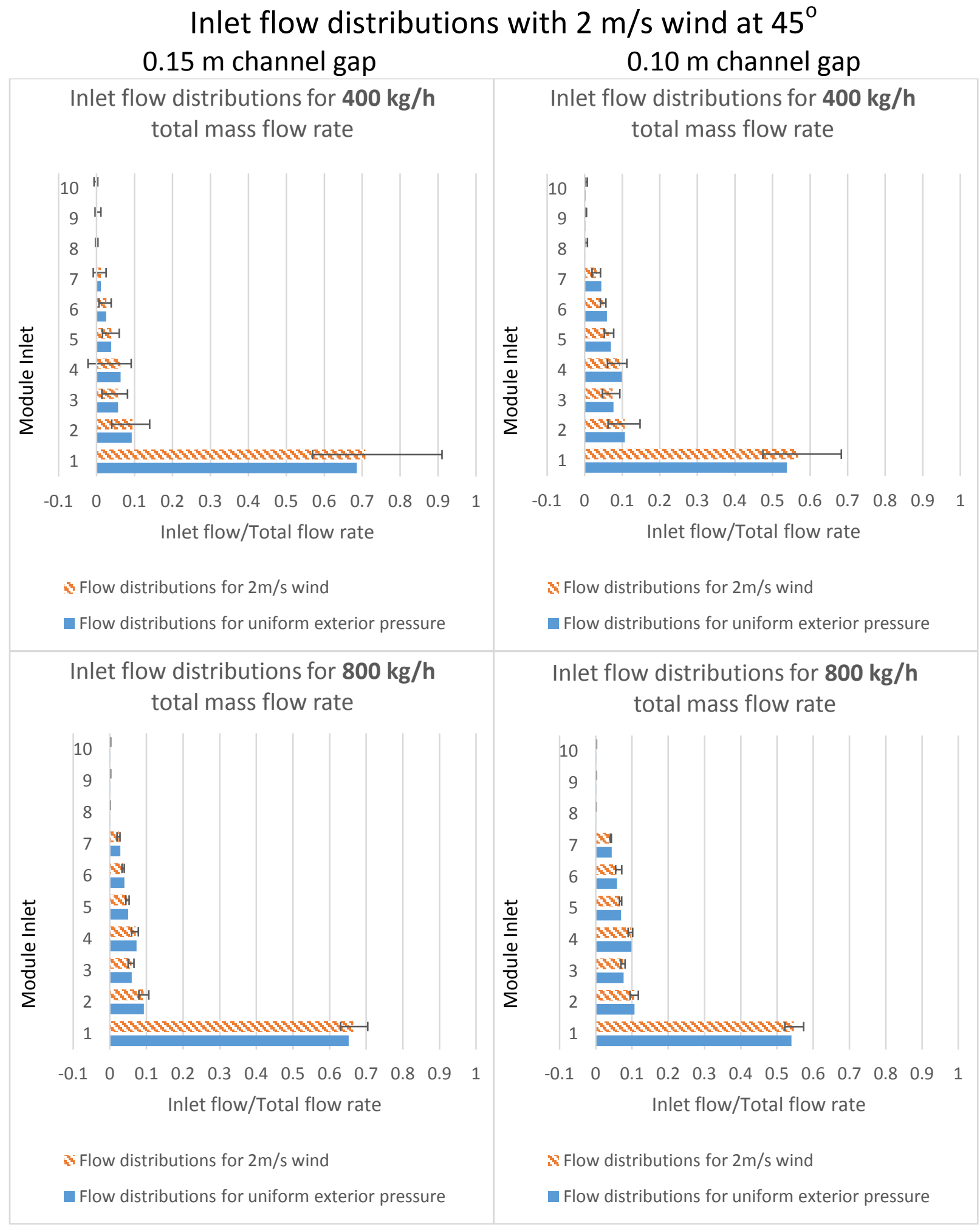

Figure 11: Normalized flow distributions of multiple-inlet systems with a $0.15 \mathrm{~m}$ and $0.10 \mathrm{~m}$ channel gap, for $2 \mathrm{~m} / \mathrm{s}$ wind at $45^{\circ}$ angle of incidence, for $400 \mathrm{~kg} / \mathrm{h}$ and $800 \mathrm{~kg} / \mathrm{h}$ total mass flow rate, for module inlets 1 to 10 (bottom to top) of the PV string. 


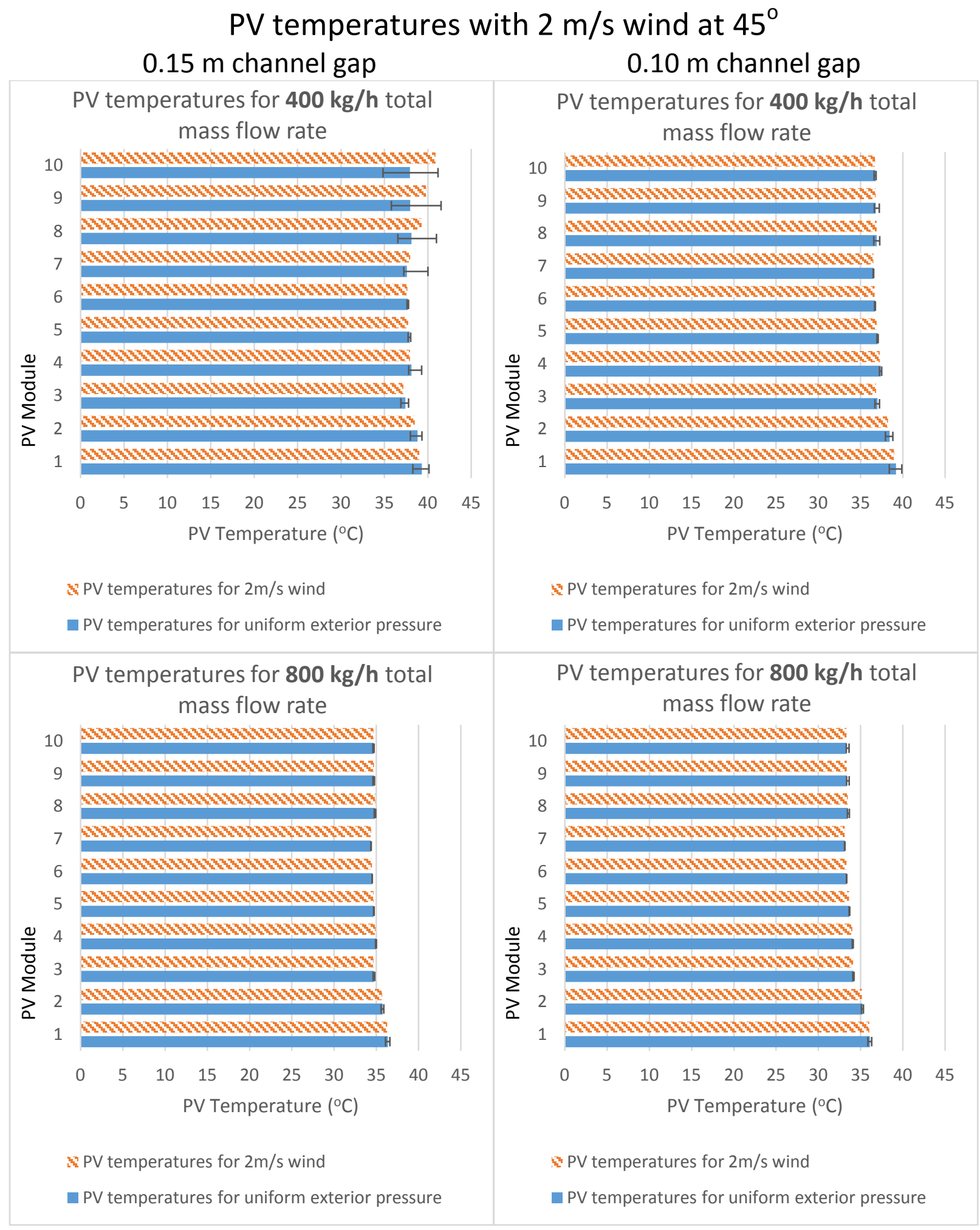

Figure 12: PV temperature distributions of multiple-inlet systems with a $0.15 \mathrm{~m}$ and $0.10 \mathrm{~m}$ channel gap, for $2 \mathrm{~m} / \mathrm{s}$ wind at $45^{\circ}$ angle of incidence, for $400 \mathrm{~kg} / \mathrm{h}$ and $800 \mathrm{~kg} / \mathrm{h}$ total mass flow rate, for modules 1 to 10 (bottom to top) of the PV string. 


\section{Summer PV temperatures for single and multiple-inlet system $400 \mathrm{~kg} / \mathrm{h}$ total mass flow rate}

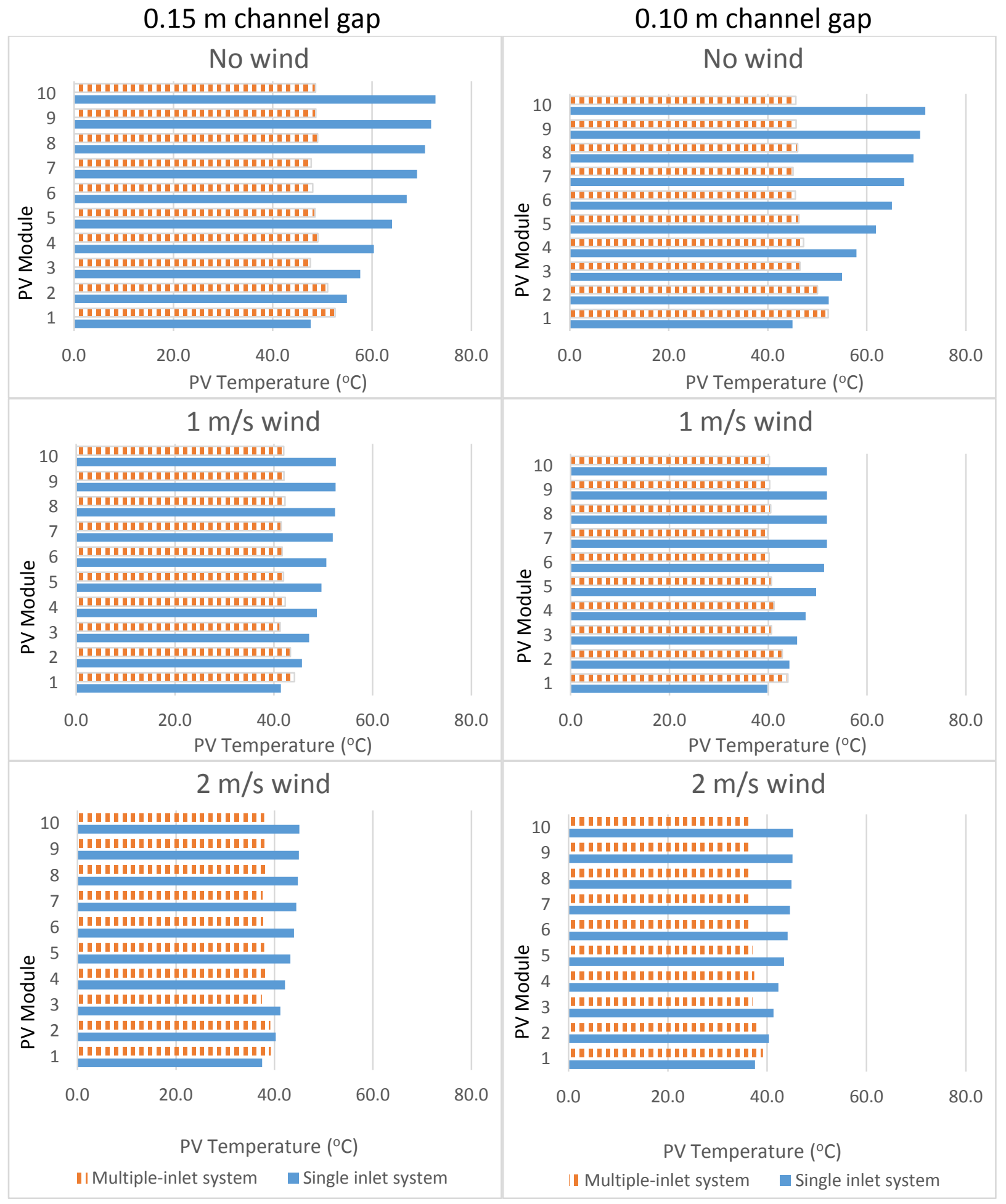

Figure 13: Comparison of PV temperatures for single and multiple-inlet systems for no wind, $1 \mathrm{~m} / \mathrm{s}$ and $2 \mathrm{~m} / \mathrm{s}$ wind and $400 \mathrm{~kg} / \mathrm{h}$ total mass flow rate, for modules 1 to 10 (bottom to top). 


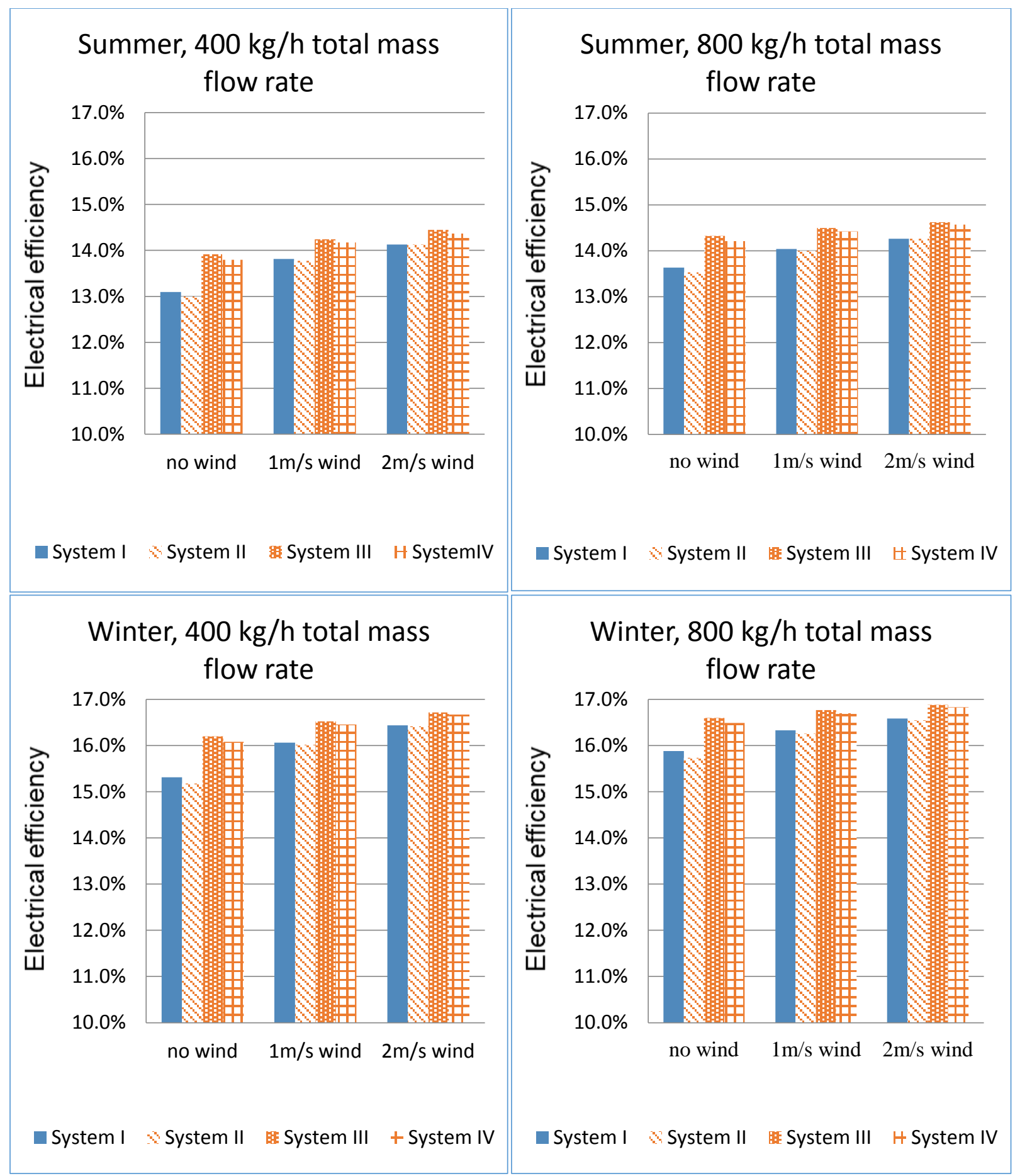

Figure 14: Electrical efficiency of the four systems for summer and winter conditions, with and without wind and at total air mass flow rate of $400 \mathrm{~kg} / \mathrm{h}$ and $800 \mathrm{~kg} / \mathrm{h}$. 


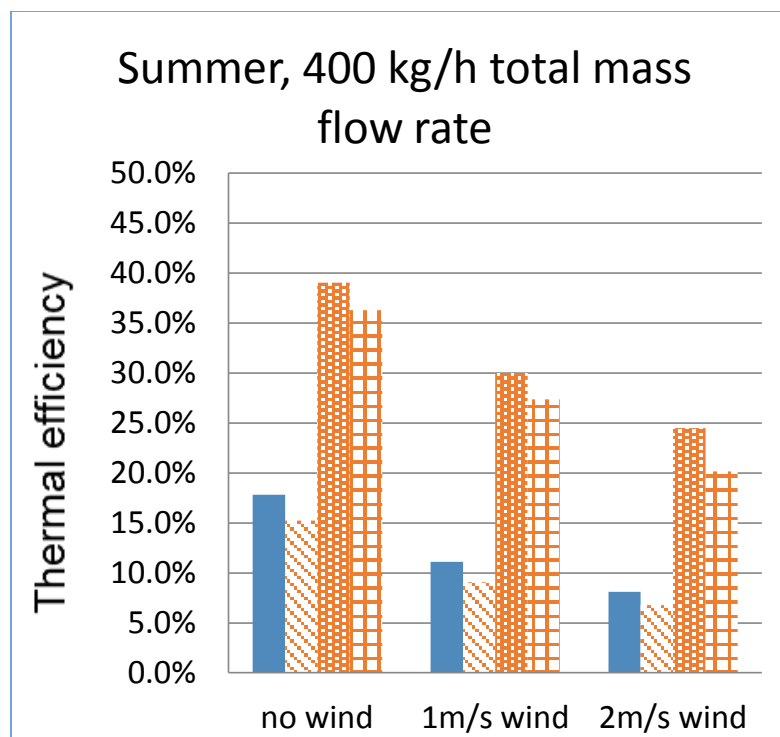

口ystem I System II 吸 System III म SystemIV

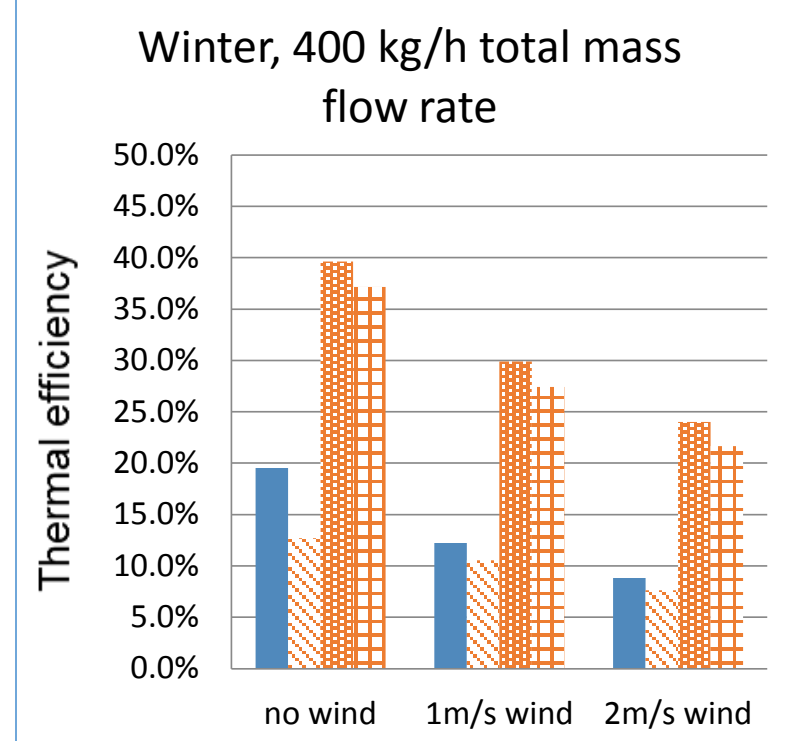

口 System I System II $\quad$ 月⿰ System III ISystem IV

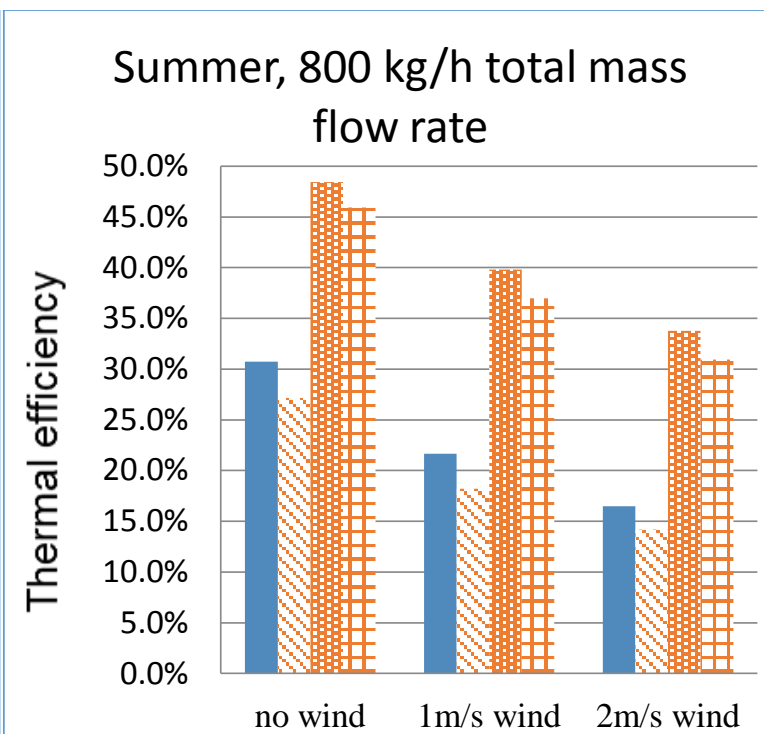

- System I System II \& \&ystem III H System IV

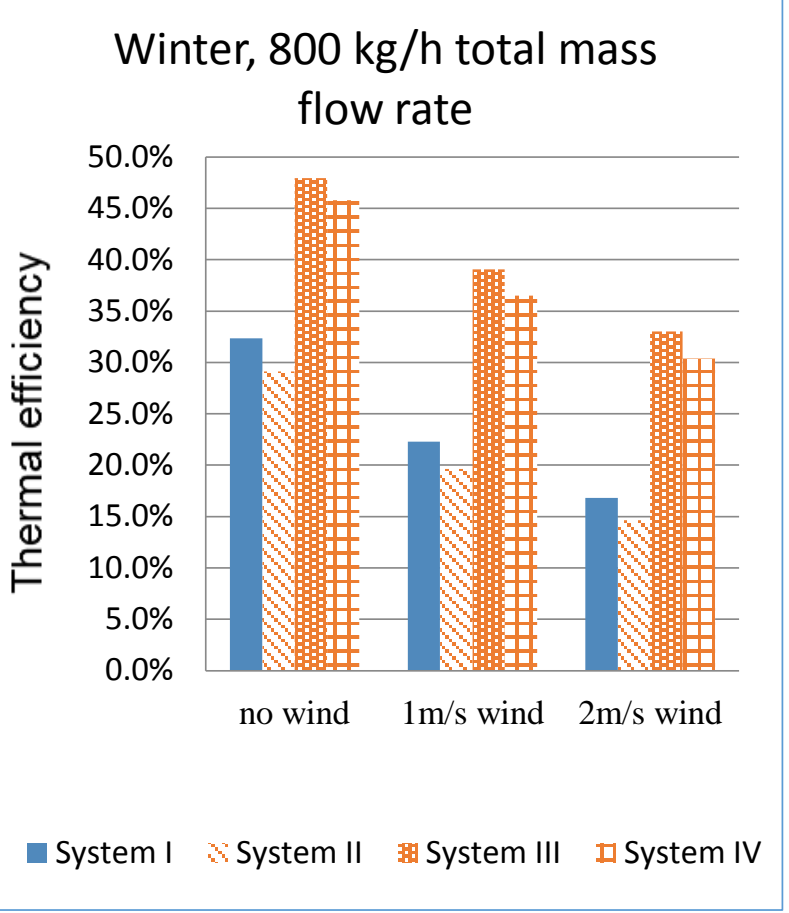

Figure 15: Thermal efficiency of the four systems for summer and winter conditions, with and without wind and at total air mass flow rate of $400 \mathrm{~kg} / \mathrm{h}$ and $800 \mathrm{~kg} / \mathrm{h}$. 
Table 1: Inlet porosities for the multiple-inlet systems.

\begin{tabular}{ll}
\hline Inlet & Porosity $(\%)$ \\
\hline 1 & 10 \\
2 & 1 \\
3 & 0.5 \\
4 & 0.5 \\
5 & 0.3 \\
6 & 0.2 \\
7 & 0.1 \\
8 & 0.01 \\
9 & 0.01 \\
10 & 0.01 \\
\hline
\end{tabular}


Table 2: Inlet flow rate distributions for multiple-inlet system with $0.1 \mathrm{~m}$ channel gap, with or without wind.

\begin{tabular}{|c|c|c|c|c|c|c|c|c|c|c|c|c|c|c|c|}
\hline \multirow{3}{*}{\multicolumn{2}{|c|}{$\begin{array}{l}\text { Total flow rate } \\
\text { Wind direction } \\
\text { Wind velocity } \\
(\mathrm{m} / \mathrm{s})\end{array}$}} & \multicolumn{7}{|c|}{$400 \mathrm{~kg} / \mathrm{h}$} & \multicolumn{7}{|c|}{$800 \mathrm{~kg} / \mathrm{h}$} \\
\hline & & \multirow{2}{*}{$\begin{array}{l}- \\
0 \\
0\end{array}$} & \multicolumn{2}{|l|}{$45^{\circ}$} & \multicolumn{2}{|l|}{$90^{\circ}$} & \multicolumn{2}{|l|}{$135^{\circ}$} & - & \multicolumn{2}{|l|}{$45^{\circ}$} & \multicolumn{2}{|l|}{$90^{\circ}$} & \multicolumn{2}{|l|}{$135^{\circ}$} \\
\hline & & & 1 & 2 & 1 & 2 & 1 & 2 & 0 & 1 & 2 & 1 & 2 & 1 & 2 \\
\hline \multirow{10}{*}{ 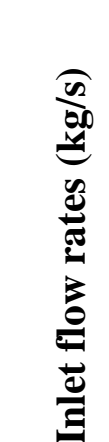 } & 1 & 215.4 & 218.3 & 227.4 & 215.7 & 217.3 & 215.7 & 217.4 & 431.7 & 433.1 & 437.5 & 437.5 & 432.4 & 431.6 & 432.6 \\
\hline & 2 & 42.7 & 42.6 & 42.8 & 42.1 & 39.9 & 42.5 & 41.6 & 85.3 & 85.3 & 85.2 & 85.2 & 84.1 & 85.2 & 84.8 \\
\hline & 3 & 30.7 & 30.6 & 29.9 & 30.8 & 31.1 & 30.7 & 30.6 & 61.3 & 61.3 & 61.0 & 61.0 & 61.6 & 61.1 & 61.3 \\
\hline & 4 & 39.5 & 39.0 & 37.6 & 39.5 & 39.7 & 39.4 & 39.3 & 78.8 & 78.5 & 77.6 & 77.6 & 78.9 & 78.6 & 78.7 \\
\hline & 5 & 28.0 & 27.5 & 26.2 & 28.1 & 28.2 & 28.0 & 27.9 & 55.9 & 55.7 & 55.0 & 55.0 & 56.0 & 56.1 & 55.8 \\
\hline & 6 & 23.6 & 22.8 & 20.3 & 23.8 & 23.8 & 23.7 & 23.4 & 47.0 & 46.6 & 45.8 & 45.8 & 47.1 & 47.6 & 46.9 \\
\hline & 7 & 17.7 & 16.8 & 12.9 & 17.6 & 17.6 & 17.6 & 17.5 & 35.2 & 34.8 & 33.4 & 33.4 & 35.1 & 35.2 & 35.2 \\
\hline & 8 & 0.6 & 0.5 & 0.7 & 0.6 & 0.6 & 0.6 & 0.6 & 1.1 & 1.1 & 1.1 & 1.1 & 1.1 & 1.1 & 1.1 \\
\hline & 9 & 0.9 & 0.9 & 1.0 & 0.9 & 0.9 & 0.9 & 0.9 & 1.8 & 1.8 & 1.7 & 1.7 & 1.8 & 1.7 & 1.8 \\
\hline & 10 & 0.9 & 0.9 & 1.1 & 0.9 & 0.9 & 0.9 & 0.9 & 1.9 & 1.9 & 1.8 & 1.8 & 1.9 & 1.8 & 1.9 \\
\hline
\end{tabular}

Table 3: Inlet flow rate distributions for multiple-inlet system with $0.15 \mathrm{~m}$ channel gap, with or without wind.

\begin{tabular}{|c|c|c|c|c|c|c|c|c|c|c|c|c|c|c|c|}
\hline \multirow{2}{*}{\multicolumn{2}{|c|}{$\begin{array}{l}\text { Total flow rate } \\
\text { Wind direction } \\
\text { Wind velocity } \\
(\mathrm{m} / \mathrm{s})\end{array}$}} & \multicolumn{7}{|c|}{$400 \mathrm{~kg} / \mathrm{h}$} & \multicolumn{7}{|c|}{$800 \mathrm{~kg} / \mathrm{h}$} \\
\hline & & $\begin{array}{l}- \\
0\end{array}$ & \multicolumn{2}{|l|}{$45^{\circ}$} & \multicolumn{2}{|l|}{$90^{\circ}$} & \multicolumn{2}{|l|}{$135^{\circ}$} & - & \multicolumn{2}{|l|}{$45^{\circ}$} & \multicolumn{2}{|l|}{$90^{\circ}$} & \multicolumn{2}{|l|}{$135^{\circ}$} \\
\hline \multirow{10}{*}{$\stackrel{ \pm}{\Xi}$} & 1 & 260.5 & 265.3 & 283.3 & 260.9 & 264.3 & 261.0 & 263.9 & 521.5 & 523.8 & 521.7 & 522.7 & 432.4 & 521.8 & 522.8 \\
\hline & 2 & 37.2 & 37.2 & 37.8 & 36.5 & 32.5 & 36.9 & 35.4 & 74.4 & 74.5 & 74.1 & 72.7 & 84.1 & 74.3 & 73.8 \\
\hline & 3 & 24.1 & 23.8 & 22.7 & 24.2 & 24.4 & 24.0 & 23.8 & 48.0 & 47.9 & 48.1 & 48.3 & 61.6 & 48.0 & 47.9 \\
\hline & 4 & 29.2 & 28.4 & 25.2 & 29.3 & 29.6 & 29.1 & 28.7 & 58.3 & 57.9 & 58.3 & 58.5 & 78.9 & 58.2 & 58.1 \\
\hline & 5 & 20.0 & 19.2 & 15.7 & 20.0 & 20.4 & 19.9 & 19.8 & 39.8 & 39.4 & 39.9 & 40.0 & 56.0 & 39.8 & 39.6 \\
\hline & 6 & 16.0 & 14.7 & 10.4 & 16.0 & 15.8 & 15.9 & 15.3 & 31.8 & 31.2 & 31.8 & 31.7 & 47.1 & 31.7 & 31.6 \\
\hline & 7 & 11.5 & 9.9 & 4.6 & 11.5 & 11.3 & 11.6 & 11.3 & 22.9 & 22.2 & 22.9 & 22.7 & 35.1 & 22.9 & 22.8 \\
\hline & 8 & 0.4 & 0.4 & 0.2 & 0.4 & 0.4 & 0.4 & 0.4 & 0.8 & 0.7 & 0.8 & 0.8 & 1.1 & 0.8 & 0.8 \\
\hline & 9 & 0.6 & 0.6 & 0.5 & 0.6 & 0.6 & 0.6 & 0.6 & 1.2 & 1.2 & 1.2 & 1.2 & 1.8 & 1.2 & 1.2 \\
\hline & 10 & 0.6 & 0.7 & -0.4 & 0.6 & 0.7 & 0.6 & 0.7 & 1.3 & 1.3 & 1.3 & 1.3 & 1.9 & 1.3 & 1.3 \\
\hline
\end{tabular}

